rounded and more anteroposteriorly compressed node. The antennæ are 10-jointed as in luzonensis, with the funicular joints 3-8 broader than long. The thorax seems to be stouter and shorter than in the species from the Philippines, but the integument is still so soft, that I can infer nothing in regard to the adult proportions of its various sclerites.

\title{
A FLIGHT OF PIERIS MONUSTE
}

I was much interested in the account by Dr. E. D. Ball and W. E. Stone of "A puzzling Butterfly Migration" (Science, vol. 68, p. 110, 1928). It reminds me of a migration which occured while I was living at St. Augustine, Florida. In June, 1881, there was a northward flight of Pieris monuste lasting for three days. On the first and second days it was a marvelous sight like a snowstorm with large flakes obscuring the view. On the second day a New York schooner ("Nellie Grant") came in. I knew the captain quite well and asked him when he first saw the flight and he said_- "Yesterday afternoon about ten miles off shore." It was the first and only flight I saw during the eight years I lived in Florida, and was noticed at the time as far north as Charleston, S.C. Many asked me the cause of this great flight. I attributed it to a search of the insect for more food plants. There are many cruciferous plants along the sea-coast that are often destroyed by the larvæ. The first brood having devoured all the food plants of the species along the more southern part of the Florida coast, the second brood was compelled to migrate, and in this case it was northward.

This flight was recorded in the American Naturalist, Vol. 15, p. 577, 1881. The report was from Bluffton, near Beaufort, S.C., and occurred June 1 and 2. They were flying "East or northeast." As they were apparently following the coast, this would naturally be the direction they would be flying east of Savannah.

C. W. Johnson. 

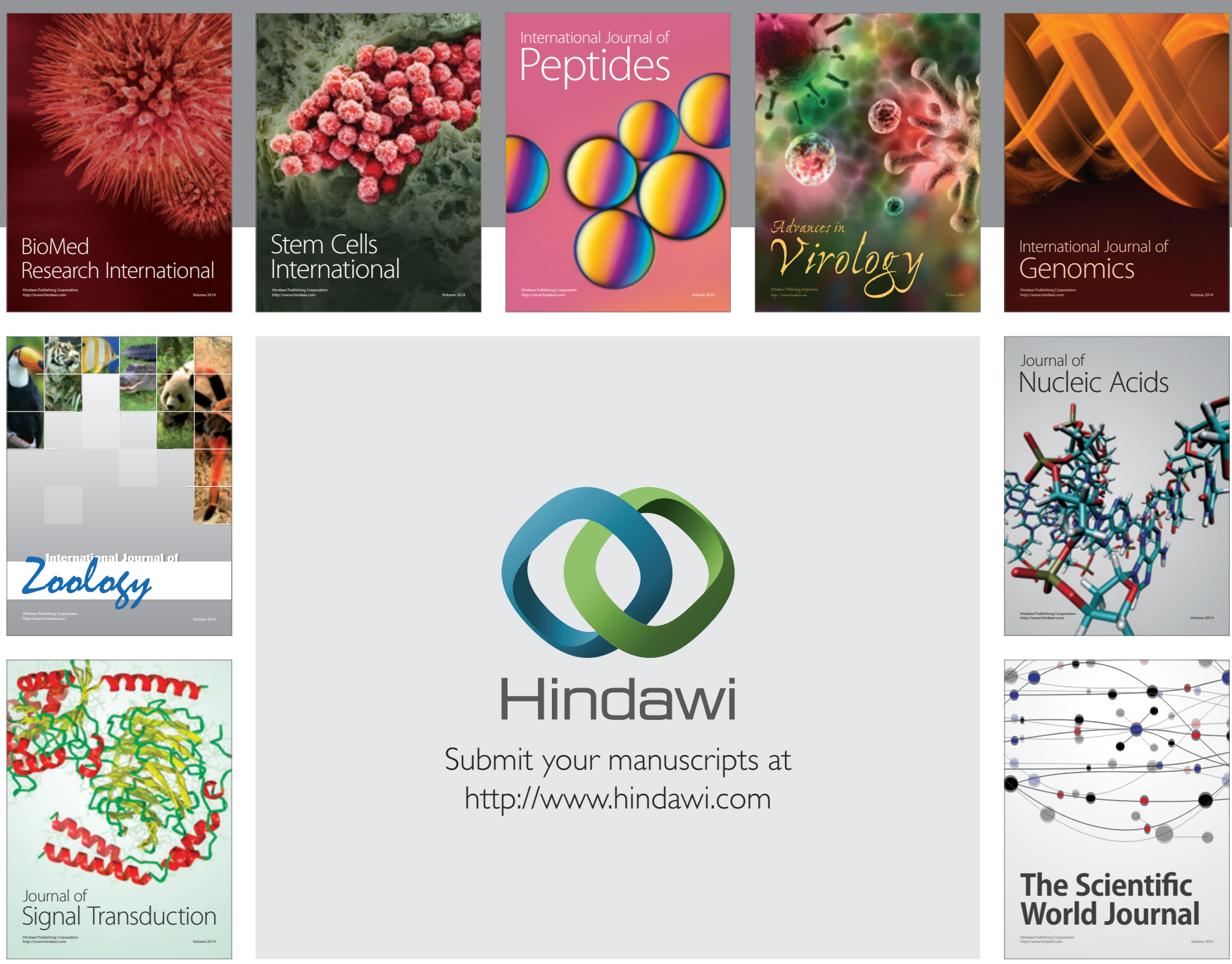

Submit your manuscripts at

http://www.hindawi.com
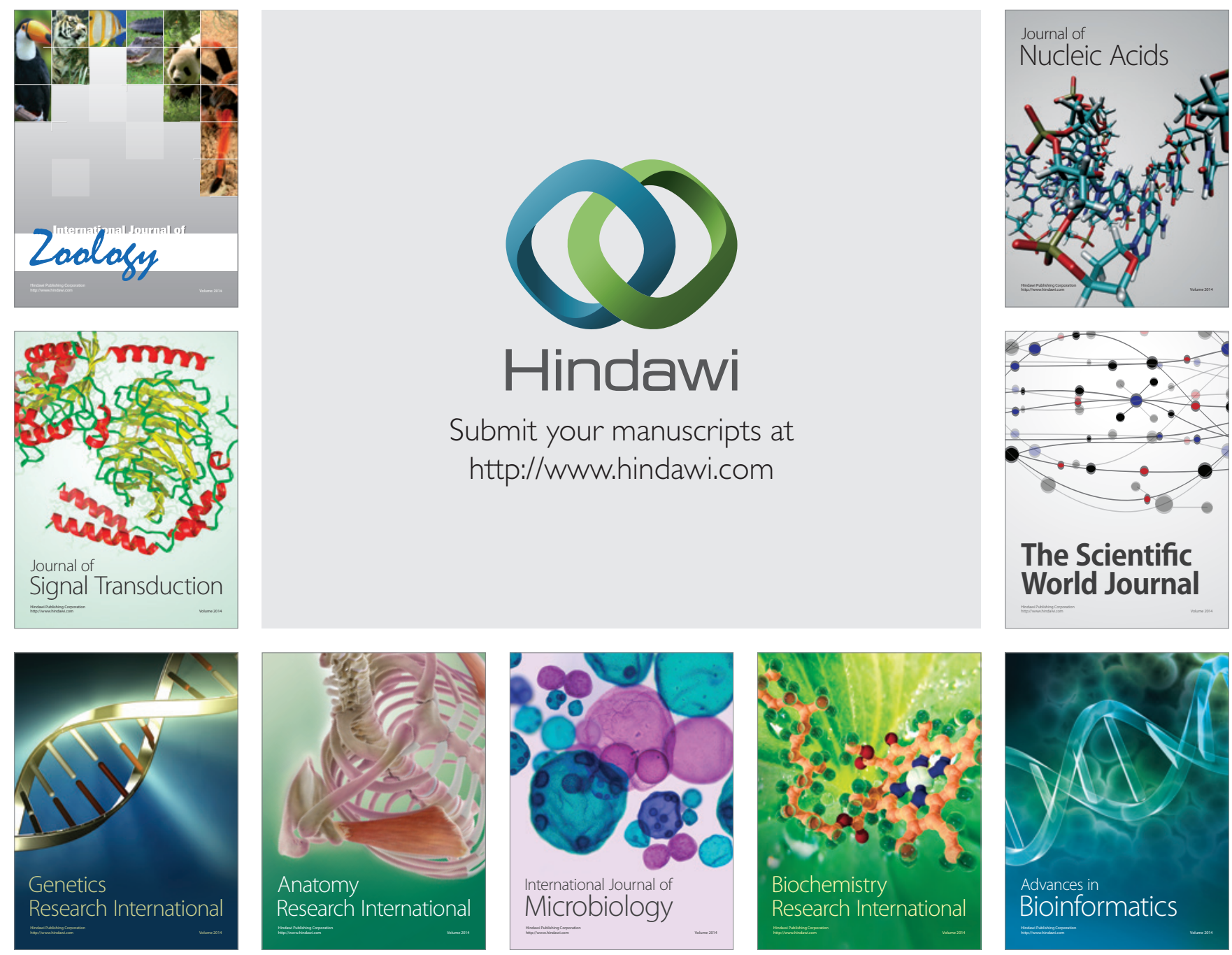

The Scientific World Journal
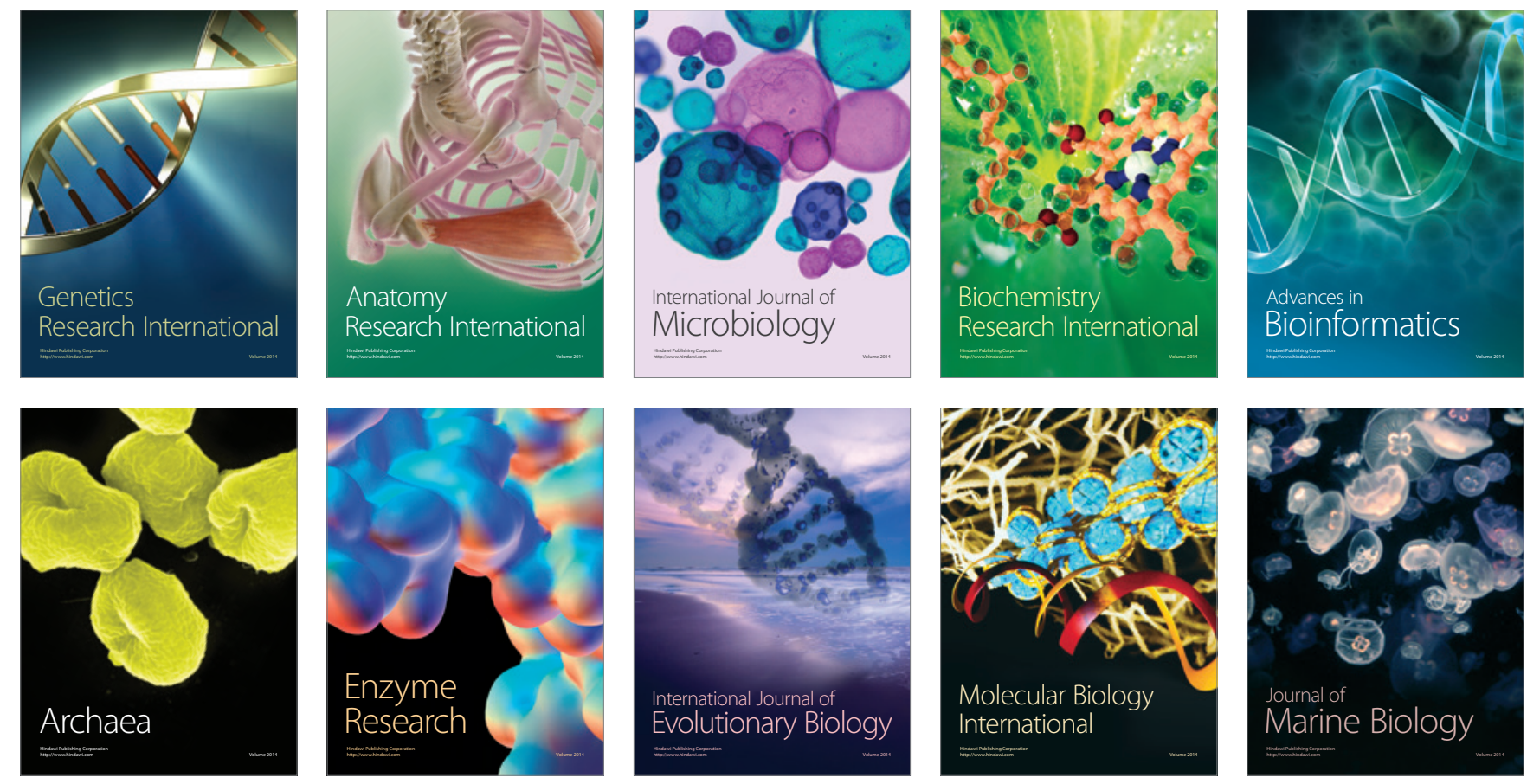